\title{
PENENTUAN NILAI MOMEN MAGNET NEODYMIUM YANG BERGERAK DI DALAM PIPA ALUMINIUM DAN KUNINGAN DENGAN METODE ANALISIS VIDEO
}

\author{
Albertus Hariwangsa Panuluh* dan Yohanes Jeverson Bulu \\ Program Studi Pendidikan Fisika, Universitas Sanata Dharma \\ Kampus III USD Maguwoharjo, Sleman, DIY 55282 \\ *Corresponding author: panuluh@usd.ac.id
}

\begin{tabular}{c|c|c} 
Diterima 22 September 2021 & Disetujui 21 Januari 2022 & Dipublikasikan 28 Januari 2022 \\
\hline
\end{tabular}

\begin{abstract}
ABSTRAK
Telah dilakukan penelitian untuk menentukan nilai momen magnet dan mengetahui hubungan diameter dalam pipa terhadap nilai momen magnet neodymium yang bergerak di dalam pipa aluminium dan kuningan dengan metode analisis video. Dipakai sistem pesawat atwood untuk merancang prosedur percobaan pengambilan data. Salah satu beban yang digantungkan di ujung tali direkam pergerakannya menggunakan kamera panasonic Hc-V30. Kemudian file video tersebut dianalisis menggunakan software Logger Pro. Dari analisis tersebut diperoleh grafik posisi fungsi waktu. Kemudian dipilih data yang menunjukkan bahwa magnet telah bergerak dengan kecepatan konstan. Nilai kemiringan dari grafik sama dengan nilai kecepatan terminal dari gerak magnet di dalam pipa. Nilai kecepatan terminal tersebut dapat digunakan untuk memperoleh nilai koefisien redaman magnetik. Kemudian nilai koefisien redaman magnetik yang diperoleh digunakan untuk memperoleh nilai momen magnetik. Dari penelitian yang telah dilakukan dapat disimpulkan bahwa nilai koefisien redaman magnetik berbanding terbalik dengan diameter dalam pipa dan berbanding lurus dengan suseptibilitas bahan. Nilai momen magnet berbanding lurus dengan diameter dalam pipa dan berbanding terbalik dengan koefisien konduktivitas bahan.
\end{abstract}

Kata kunci: pipa aluminium dan kuningan, magnet neodymium, analisis video, Logger Pro, momen magnet

\begin{abstract}
Research has been carried out to determine the value of the magnetic moment and determine the relationship between the inside diameter of the tube and the neodymium magnetic moment that moves in the aluminum and brass pipe using the video analysis method. We use the Atwood machine to design experimental data collection procedures. One of the weights hanging from the rope's end was recorded movement using a Panasonic Hc-V30 camera. Then the video file is analyzed using Logger Pro software. From this analysis, we obtain a graph of the position of the function of time. We then selected data showing that the magnet has been moving at a constant speed. The slope value of the graph is equal to the terminal velocity of the magnet's motion in the tube. The terminal velocity can be used to obtain the value of the magnetic damping coefficient. Then the magnetic damping coefficient value obtained is used to get the value of the magnetic moment. From this research, we identify that the value of the magnetic damping coefficient is inversely proportional to the inside diameter of the pipe and directly proportional to the material's susceptibility. The magnetic moment value is directly proportional to the inside diameter of the tube and inversely proportional to the conductivity coefficient of the material.
\end{abstract}

Keywords: aluminium and brass pipes, Logger Pro, magnetic moment, neodymium magnets, video analysis

\section{PENDAHULUAN}

Salah satu hal yang paling penting dalam ilmu fisika adalah pengukuran. Pengukuran yang pada awalnya dilakukan secara konvensional, sekarang telah dimudahkan dengan perkembangan teknologi yang begitu pesat. Sebagai contohnya, telepon genggam yang dahulu hanya dipakai untuk komunikasi sekarang juga dapat digunakan untuk mengukur besaran-besaran fisika. Misalkan penggunaan sensor dari smartphone untuk mengukur nilai percepatan gravitasi (1-3), medan magnetik (4,5), dan kecepatan sudut (6). Selain sensor, smartphone juga dilengkapi dengan kamera 
yang dapat digunakan untuk memotret maupun merekam video. Foto maupun video tersebut dapat diolah dan dianalisis menggunakan berbagai software, salah satunya ialah Logger Pro. Telah banyak penelitian menggunakan metode analisis dengan bantuan Logger Pro, di antaranya pengukuran modulus young senar pancing (7), pengukuran modulus geser baja (8) dan penentuan nilai viskositas air (9-11).

Dari uraian di atas menunjukkan peranan positif dari perkembangan teknologi terhadap ilmu fisika bahwa dalam melakukan eksperimen sederhana saat ini tidak perlu menggunakan alat yang mahal. Penerapan teknologi ini juga dapat digunakan sebagai salah satu metode pembelajaran fisika di sekolah, khususnya materi fisika yang sulit. Dalam penelitian ini, peneliti akan meneliti mengenai redaman magnetik (12). Interaksi antara magnet dengan bahan berkonduktor listrik dapat menyebabkan suatu redaman magnetik. Magnet yang bergerak di ruang bebas udara, waktu untuk bergeraknya lebih cepat dibandingkan waktu bergerak untuk magnet yang bergerak di daerah sekitar bahan berkonduktor listrik. Lebih lamanya waktu untuk magnet yang bergerak di sekitar suatu alat berbahan konduktor listrik diakibatkan karena adanya redaman magnetik.

Redaman magnetik antara magnet dengan bahan konduktor listrik dapat dijelaskan dengan teori elektromagnetik khususnya yaitu hukum Faraday dan hukum Lenz tentang induksi magnetik. Melalui konsep hukum Faraday dan hukum Lenz, redaman magnetik pada interaksi antara magnet dengan bahan konduktor listrik dapat dijelaskan bahwa interaksi antara magnet dengan bahan berbahan konduktor listrik yang bergerak terhadap satu dengan yang lainnya menimbulkan perubahan fluks magnetik sehingga membangkitkan arus induksi atau arus eddy. Kemudian arus induksi menghasilkan fluks pelawan yang melawan perubahan fluks magnetik penyebabnya. Timbulnya fluks pelawan menghasilkan gaya redaman magnetik (13).

Penelitian mengenai magnet yang bergerak pada pipa konduktor pernah dilakukan $(14,15)$. Pada penelitian tersebut digunakan Rotary Motion Sensor untuk menentukan kecepatan terminal dari magnet yang bergerak di dalam pipa konduktor. Namun, tidak semua orang memiliki sensor tersebut. Maka, dalam penelitian ini kecepatan terminal dari magnet diukur menggunakan metode analisis video dengan Logger Pro. Kemudian dari nilai kecepatan terminal dapat diperoleh nilai konstanta redaman magnetik yang selanjutnya dapat digunakan untuk menentukan nilai momen magnetik.

\section{METODE PENELITIAN}

Pada penelitian ini magnet yang digunakan adalah magnet neodymium berbentuk tabung dengan masssa $(5,7 \pm 0,8) \times 10^{-3} \mathrm{~kg}$, diameter $(9,712 \pm 0,008) \times 10^{-3} \mathrm{~m}$, dan tinggi $(1,005 \pm 0,003) \times$ $10^{-2} \mathrm{~m}$. Pipa konduktor yang digunakan ada dua jenis, yaitu aluminium dan kuningan. Kedua pipa memiliki panjang dan tebal yang sama secara berturut-turut $1 \mathrm{~m}$ dan $1,2 \mathrm{~mm}$, namun memiliki diameter dalam yang berbeda-beda masing-masing tiga buah. Pipa aluminium memiliki diameter dalam $(22,180 \pm 0,020) \mathrm{mm},(28,256 \pm 0,007) \mathrm{mm}$, dan $(35,032 \pm 0,005) \mathrm{mm}$. Sedangkan pipa kuningan memiliki diameter dalam $(22,332 \pm 0,005) \mathrm{mm},(28,348 \pm 0,008) \mathrm{mm}$, dan $(35,064 \pm$ $0,007) \mathrm{mm}$.

Susunan alat eksperimen dapat dilihat pada gambar 1 mirip seperti yang dilakukan oleh (15). Perbedaannya terletak pada metode yang digunakan dalam penelitian ini menggunakan analisis video. Saat beban penggantung 10 gram dilepas, magnet neodymium akan bergerak naik memasuki pipa aluminium maupun pipa kuningan. Pergerakan beban penggantung direkam menggunakan kamera video Panasonic HC-V380. Kemudian file dari rekaman video tersebut dianalisis di laptop yang sudah terinstal aplikasi Logger Pro. Lintasan beban penggantung yang bergerak jatuh ke bawah diberi midline di sampingnya sebagai standar jarak. Dari hasil analisis akan diperoleh data dalam bentuk grafik posisi fungsi waktu. Kemudian dari grafik dipilih titik-titik yang membentuk garis lurus karena pada kondisi tersebut magnet mengalami kecepatan konstan atau kecepatan terminal karena adanya redaman magnetik. Nilai kecepatan terminal yang diperoleh dari grafik disubstitusikan ke persamaan gerak magnet teredam untuk mendapatkan nilai koefisien redaman magnetik. Pengulangan dilakukan sebanyak 5 kali.

Kemudian nilai koefisien redaman magnetik yang diperoleh disubsitusikan ke persamaan

Penentuan Nilai Momen Magnet Neodymium yang Bergerak di dalam Pipa Aluminium dan Kuningan dengan Metode....

Albertus Hariwangsa Panuluh dan Yohanes Jeverson Bulu 
momen magnet untuk memperoleh nilai momen magnetik. Dalam perhitungan momen magnet, ada beberapa besaran yang sudah diketahui nilainya yaitu nilai faktor redaman $(f)$ dan konduktivitas listrik pipa aluminium dan pipa kuningan. Kedua pipa tersebut diasumsikan pipa murni sehingga setelah diperoleh nilai koefisien redaman magnetik maka dapat dihitung nilai momen magnet.

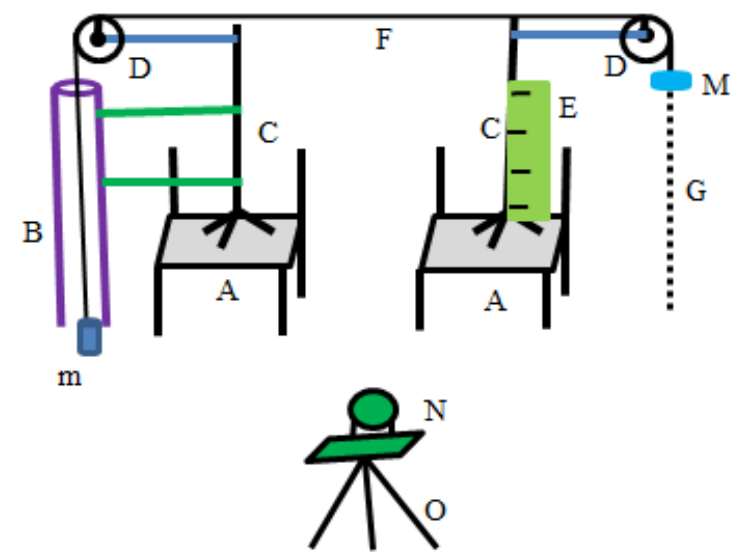

Gambar 1. Susunan alat dengan menggunakan metode rekaman video (analisis video). A:kursi, m: magnet neodymium, B: pipa, D: katrol, F: tali penggantung, C: statif, M:beban, E: midline/penggaris, G: tripod, H: kamera.

\section{HASIL DAN PEMBAHASAN}

\subsection{Hasil Penelitian}

Langkah pertama dalam penelitian ini adalah menghitung kecepatan terminal magnet neodymium yang bergerak di dalam pipa aluminium dan kuningan. Seperti yang disebutkan pada Bab II, terdapat variasi 3 diameter dalam pipa. Nilai kecepatan terminal ditentukan menggunakan analisis video menggunakan software LoggerPro. Sebagai contoh, grafik hubungan posisi terhadap waktu dari pergerakan magnet neodymium di dalam pipa aluminium dan pipa kuningan disajikan pada Gambar 2 dan Gambar 3 berturut-turut.

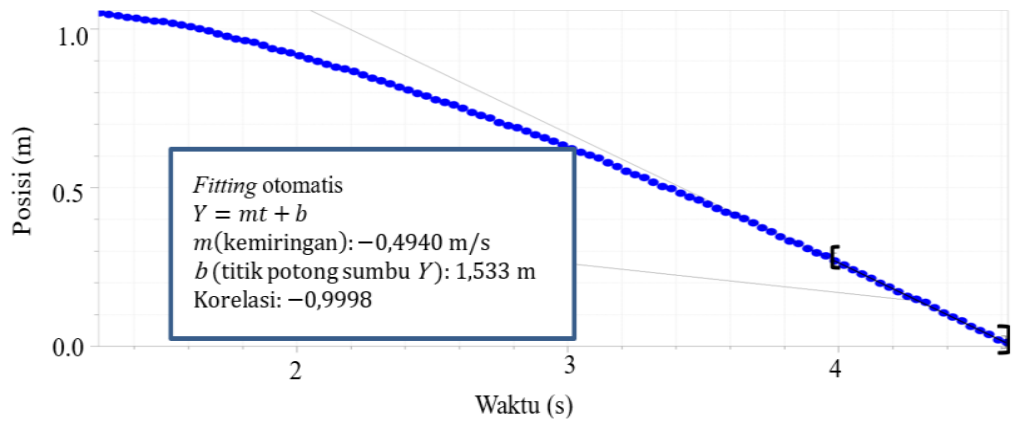

Gambar 2. Grafik posisi terhadap waktu dari pergerakan magnet neodymium di dalam pipa aluminium dengan diameter dalam $(28,256 \pm 0,007) \mathrm{mm}$.

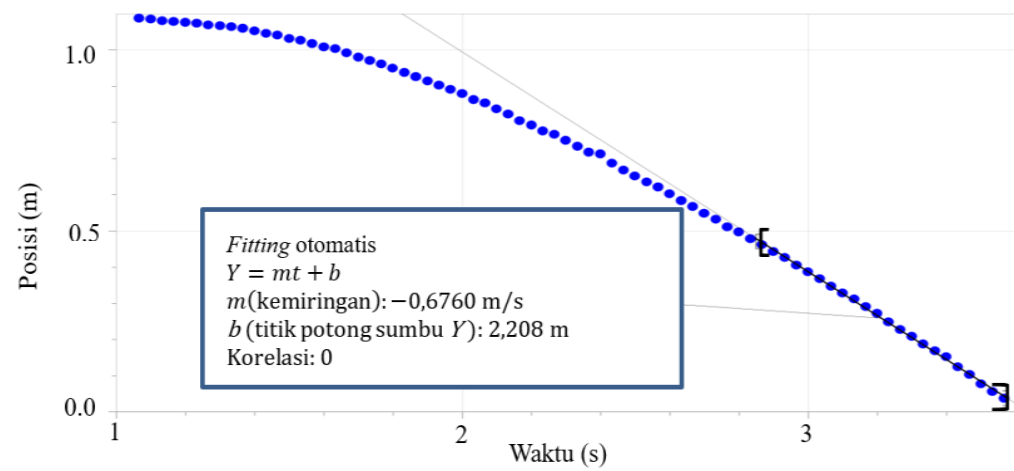

Gambar 3. Grafik posisi terhadap waktu dari pergerakan magnet neodymium di dalam pipa kuningan dengan diameter dalam $(28,348 \pm 0,008) \mathrm{mm}$. 
Pada Gambar 2 dan Gambar 3 dapat dilihat bahwa semakin lama, magnet akan bergerak dengan kecepatan konstan yang tak lain adalah kecepatan terminal. Data yang menunjukkan hal tersebut kemudian difit linier sehingga dapat diperoleh nilai kecepatan terminal yang merupakan gradien (slope) dari grafik. Pengambilan data ini dilakukan sebanyak 5 kali untuk setiap diameter dalam pipa sehingga diperoleh nilai kecepatan terminal rerata beserta ralatnya (ketidakpastian pengukuran) untuk setiap diameter dalam pipa aluminium dan pipa kuningan yang masing-masing disajikan pada Tabel 1 dan Tabel 2 berturut-turut.

Tabel 1. Pengukuran kecepatan terminal magnet neodymium yang bergerak dalam pipa aluminium sebanyak 5 kali pengambilan data setiap diameter

\begin{tabular}{|c|c|c|c|}
\hline No & $D(\mathrm{~mm})$ & $\begin{array}{c}\text { Pengukuran kecepatan terminal } v_{t} \\
(\mathrm{~m} / \mathrm{s}) \text { dari } 5 \text { kali pengambilan data } \\
\text { untuk setiap diameter }\end{array}$ & $\left(\bar{v}_{t} \pm \Delta v_{t}\right) \mathrm{m} / \mathrm{s}$ \\
\hline \multirow{5}{*}{1} & \multirow{5}{*}{$(22,180 \pm 0,020)$} & 0,2966 & \multirow{5}{*}{$(0,292 \pm 0,002)$} \\
\hline & & 0,2914 & \\
\hline & & 0,2893 & \\
\hline & & 0,2849 & \\
\hline & & 0,2978 & \\
\hline \multirow{5}{*}{2} & \multirow{5}{*}{$(28,256 \pm 0,007)$} & 0,4822 & \multirow{5}{*}{$(0,486 \pm 0,002)$} \\
\hline & & 0,4940 & \\
\hline & & 0,4861 & \\
\hline & & 0,4875 & \\
\hline & & 0,4806 & \\
\hline \multirow{5}{*}{3} & \multirow{5}{*}{$(35,032 \pm 0,005)$} & 0,6668 & \multirow{5}{*}{$(0,667 \pm 0,008)$} \\
\hline & & 0,6756 & \\
\hline & & 0,6720 & \\
\hline & & 0,6853 & \\
\hline & & 0,6371 & \\
\hline
\end{tabular}

Tabel 2. Pengukuran kecepatan terminal magnet neodymium yang bergerak dalam pipa kuningan sebanyak 5

\begin{tabular}{|c|c|c|c|}
\hline No & $D(\mathrm{~mm})$ & $\begin{array}{l}\text { Pengukuran kecepatan terminal } v_{t} \\
(\mathrm{~m} / \mathrm{s}) \text { dari } 5 \text { kali pengambilan data } \\
\text { untuk setiap diameter }\end{array}$ & $\left(\bar{v}_{t} \pm \Delta v_{t}\right) \mathrm{m} / \mathrm{s}$ \\
\hline \multirow{6}{*}{1} & \multirow{5}{*}{$(22,332 \pm 0,005)$} & 0,4643 & \multirow{6}{*}{$(0,457 \pm 0,005)$} \\
\hline & & 0,4649 & \\
\hline & & 0,4535 & \\
\hline & & 0,4402 & \\
\hline & & 0,4615 & \\
\hline & \multirow{5}{*}{$(28,348 \pm 0,008)$} & 0,6874 & \\
\hline \multirow{4}{*}{2} & & 0,6760 & \multirow{4}{*}{$(0,679 \pm 0,005)$} \\
\hline & & 0,6694 & \\
\hline & & 0,6937 & \\
\hline & & 0,6689 & \\
\hline \multirow{5}{*}{3} & \multirow{5}{*}{$(35,064 \pm 0,007)$} & 0,8986 & \multirow{5}{*}{$(0,8971 \pm 0,0007)$} \\
\hline & & 0,8976 & \\
\hline & & 0,8970 & \\
\hline & & 0,8944 & \\
\hline & & 0,8969 & \\
\hline
\end{tabular}

Adapun perhitungan ketidakpastian (ralat) kecepatan terminal menggunaan Persamaan 1 berikut ini 


$$
\Delta v_{t}=\sqrt{\frac{\sum_{i}^{n}\left(\overline{v_{t}}-v_{t_{i}}\right)^{2}}{n(n-1)}}
$$

dengan $\Delta v_{t}=$ ralat kecepatan terminal, $\overline{v_{t}}=$ rerata kecepatan terminal, $v_{t_{i}}=$ kecepatan terminal pengambilan data ke- $i$, dan $n=$ jumlah pengambilan data.

Kemudian nilai kecepatan terminal disubstitusikan ke Persamaan 2 berikut ini untuk memperoleh nilai koefisien redaman magnetik

$$
k=\frac{(M-m)}{v_{t}} g
$$

dengan $k=$ koefisien redaman magnetik $\left(\mathrm{kg} / \mathrm{s}^{2}\right), v_{t}=$ kecepatan terminal $(\mathrm{m} / \mathrm{s}), g=$ percepatan gravitasi bumi $\left(\mathrm{m} / \mathrm{s}^{2}\right), m=$ massa magnet neodymium, dan $M=$ massa beban penggantung. Pada Tabel 3 dan Tabel 4 disajikan nilai kecepatan terminal dan koefisien redaman magnetik dengan variasi diameter dalam pipa aluminium dan kuningan berturut-turut.

Tabel 3. Pengukuran koefisien redaman magnetik untuk magnet neodymium yang bergerak dalam pipa

\begin{tabular}{cccc}
\hline \multicolumn{3}{c}{ aluminium } \\
\hline 1 & $\mathrm{D}(\mathrm{mm})$ & $\left(\bar{v}_{t} \pm \Delta v_{t}\right) \mathrm{m} / \mathrm{s}$ & $(k \pm \Delta k) \times 10^{-1} \mathrm{~kg} / \mathrm{s}$ \\
2 & $(22,180 \pm 0,020)$ & $(0,292 \pm 0,002)$ & $(1,4 \pm 0,2)$ \\
3 & $(35,256 \pm 0,007)$ & $(0,486 \pm 0,002)$ & $(0,9 \pm 0,1)$ \\
\hline
\end{tabular}

Tabel 4. Pengukuran koefisien redaman magnetik untuk magnet neodymium yang bergerak dalam pipa

\begin{tabular}{cccc}
\multicolumn{3}{c}{ kuningan } \\
\hline No & $D(\mathrm{~mm})$ & $\left(\bar{v}_{t} \pm \Delta v_{t}\right) \mathrm{m} / \mathrm{s}$ & $(k \pm \Delta k) \times 10^{-1} \mathrm{~kg} / \mathrm{s}$ \\
\hline 1 & $(22,332 \pm 0,005)$ & $(0,457 \pm 0,005)$ & $(0,9 \pm 0,1)$ \\
2 & $(28,348 \pm 0,008)$ & $(0,679 \pm 0,005)$ & $(0,6 \pm 0,1)$ \\
3 & $(35,064 \pm 0,007)$ & $(0,8971 \pm 0,0007)$ & $(0,47 \pm 0,08)$ \\
\hline
\end{tabular}

Penentuan nilai ketidakpastian (ralat) koefisien redaman magnetik yang tersaji pada Tabel 3 dan 4 menggunakan persamaan 3 berikut

$$
\Delta k=\sqrt{\left(\frac{g}{\bar{v}_{t}} \Delta m\right)^{2}+\left(\frac{(M-m) g}{\bar{v}_{t}^{2}} \Delta v_{t}\right)^{2}}
$$

Kemudian nilai $k$ yang diperoleh disubsitusikan ke persamaan 4 untuk memperoleh nilai $\mu^{\prime 2}(15)$

$$
k=\frac{18 \pi f \sigma h \mu^{\prime 2}}{r^{4}}
$$

dengan $f$ : faktor numerik nilainya sama dengan 0,$0614 ; h:$ ketebalan pipa; $\sigma$ : konduktivitas bahan; $r$ : jari-jari pipa dan $\mu^{\prime}$ : hasil dari perkalian antara momen magnetik $(\mu)$ dengan $\mu_{o} / 4 \pi$. Jika ditulisakan bentuk persamaan yaitu:

$$
\mu^{\prime}=\mu \frac{\mu_{0}}{4 \pi}
$$

dengan $\mu_{o}$ merupakan permeabilitas bahan dan besarnya $4 \pi \times 10^{-7} \mathrm{~Wb} /$ Am. Nilai konduktivitas bahan aluminium dan kuningan adalah $3,5 \times 10^{7} \Omega^{-1} \mathrm{~m}^{-1}$ dan $1,7 \times 10^{7} \Omega^{-1} \mathrm{~m}^{-1}$ berturut-turut. Kemudian nilai $\mu^{\prime}$ yang diperoleh disubsitusikan ke persamaan 3 untuk memperoleh nilai momen magnetik. Nilai pengukuran momen magnetik disajikan pada Tabel 5 dan Tabel 6. 
Tabel 5. Pengukuran momen magnet neodymium yang bergerak di dalam pipa aluminium

\begin{tabular}{cccc}
\hline No & $D(\mathrm{~mm})$ & $(k \pm \Delta k) \times 10^{-1} \mathrm{~kg} / \mathrm{s}$ & $(\mu \pm \Delta \mu) \mathrm{A} \cdot \mathrm{m}^{2}$ \\
\hline 1 & $(22,180 \pm 0,020)$ & $(1,4 \pm 0,2)$ & $(4,8 \pm 0,7)$ \\
2 & $(28,256 \pm 0,007)$ & $(0,9 \pm 0,1)$ & $(6,3 \pm 0,7)$ \\
3 & $(35,032 \pm 0,005)$ & $(0,6 \pm 0,1)$ & $(8 \pm 1)$ \\
\hline
\end{tabular}

Tabel 6. Pengukuran momen magnet neodymium yang bergerak di dalam pipa kuningan

\begin{tabular}{cccc}
\hline No & $D(\mathrm{~mm})$ & $(k \pm \Delta k) \times 10^{-1} \mathrm{~kg} / \mathrm{s}$ & $(\mu \pm \Delta \mu) \mathrm{A} \cdot \mathrm{m}^{2}$ \\
\hline 1 & $(22,332 \pm 0,005)$ & $(0,9 \pm 0,1)$ & $(5,6 \pm 0,6)$ \\
2 & $(28,348 \pm 0,008)$ & $(0,6 \pm 0,1)$ & $(7 \pm 1)$ \\
3 & $(35,064 \pm 0,007)$ & $(0,47 \pm 0,08)$ & $(10 \pm 2)$ \\
\hline
\end{tabular}

Penentuan nilai ketidakpastian (ralat) koefisien redaman magnetik yang tersaji pada Tabel 5 dan 6 menggunakan persamaan 6 berikut

$$
\Delta \mu=\sqrt{\left(\frac{\Delta k}{k}\right)^{2}} \mu
$$

\subsection{Pembahasan}

Penelitian penentuan nilai momen magnetik pada gerak magnet di dalam pipa aluminium dan kuningan dengan metode analisis video telah berhasil dilakukan. Data hasil rekaman gerak magnet di dalam pipa ditampilkan langsung di Logger Pro dalam bentuk grafik posisi fungsi waktu. Dari grafik pada Gambar 2 dan Gambar 3 dapat ditentukan kecepatan terminal dari magnet neodymium. Kemudian koefisien redaman magnetik dapat diperoleh melalui Persamaan 2 yang nilainya secara lengkap disajikan pada Tabel 3 dan Tabel 4. Dapat dilihat bahwa nilai koefisien redaman magnetik berbanding terbalik terhadap diameter dalam pipa seperti yang ditunjukkan pada Gambar 4 . Berbanding terbaliknya kedua besaran yaitu diameter dalam pipa dan koefisien redaman magnetik dikarenakan ketika diameter dalam pipa yang digunakan semakin besar, maka jumlah garis-garis medan magnet yang sama menembus dinding pipa semakin kecil sehingga fluks magnet yang dihasilkan juga semakin kecil. Semakin kecil fluks magnetik yang dihasilkan akan menyebabkan arus eddy atau arus induksi magnetik juga semakin kecil sehingga menyebabkan medan magnet induksi juga semakin kecil. Medan magnet induksi inilah yang meredam magnet neodymium.

Hasil lain yang diperoleh dari penelitian ini adalah untuk diameter dalam pipa yang hampir sama, nilai koefisien redaman magnetik lebih besar di pipa aluminium dibandingkan di pipa kuningan seperti ditunjukkan pada Gambar 4. Hal ini disebabkan karena tingkat suseptibilitas magnetik dari pipa aluminium lebih besar dibandingkan dengan tingkat suseptibilitas pipa kuningan (16). Suseptibilitas merupakan tingkat kemagnetan suatu bahan untuk termagnetisasi atau tingkat kemagnetan suatu bahan untuk ditarik oleh magnet yang memiliki medan magnet yang kuat.

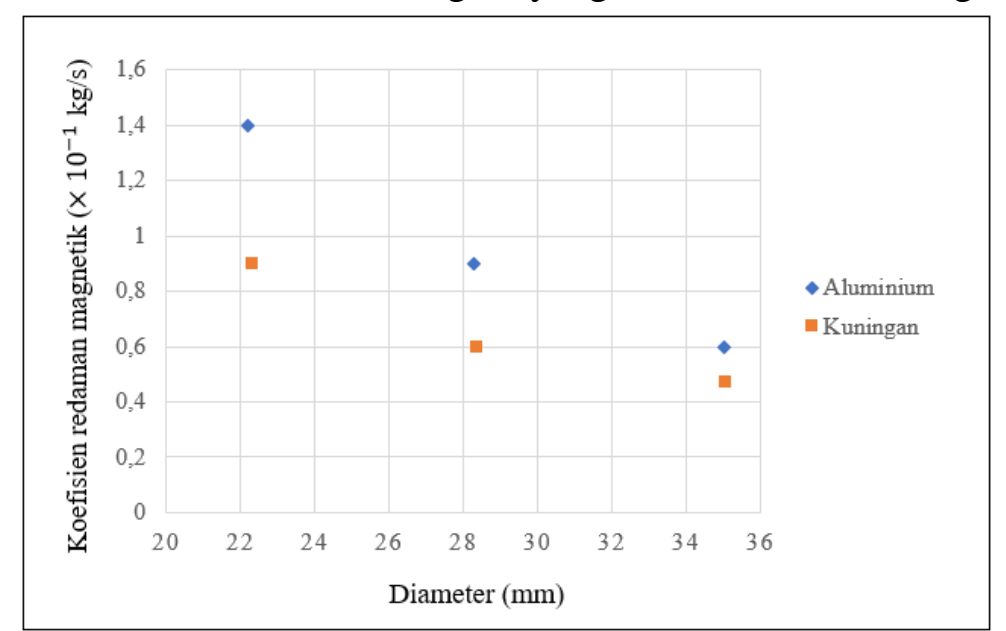

Gambar 4. Grafik koefisien redaman magnetik terhadap diameter dalam pipa aluminium dan kuningan. 
Selanjutnya nilai koefisien redaman magnetik disubstitusikan ke Persamaan 4 yang kemudian digunakan untuk mencari nilai $\mu^{\prime 2}$. Nilai momen magnet dapat diperoleh dengan menggunakan Persamaan 5. Secara lengkap hasil perhitungan nilai momen magnet dapat dilihat dari Tabel 5 dan Tabel 6. Nilai momen magnetik berbanding lurus dengan diameter dalam pipa, namun berbanding terbalik dengan koefisien konduktivitas bahan seperti yang ditampilkan pada Gambar 5. Nilai konduktivitas aluminium lebih besar daripada kuningan sehingga secara umum untuk diameter dalam yang sama, nilai momen magnet neodymiun di dalam pipa aluminium lebih kecil daripada di dalam pipa kuningan.

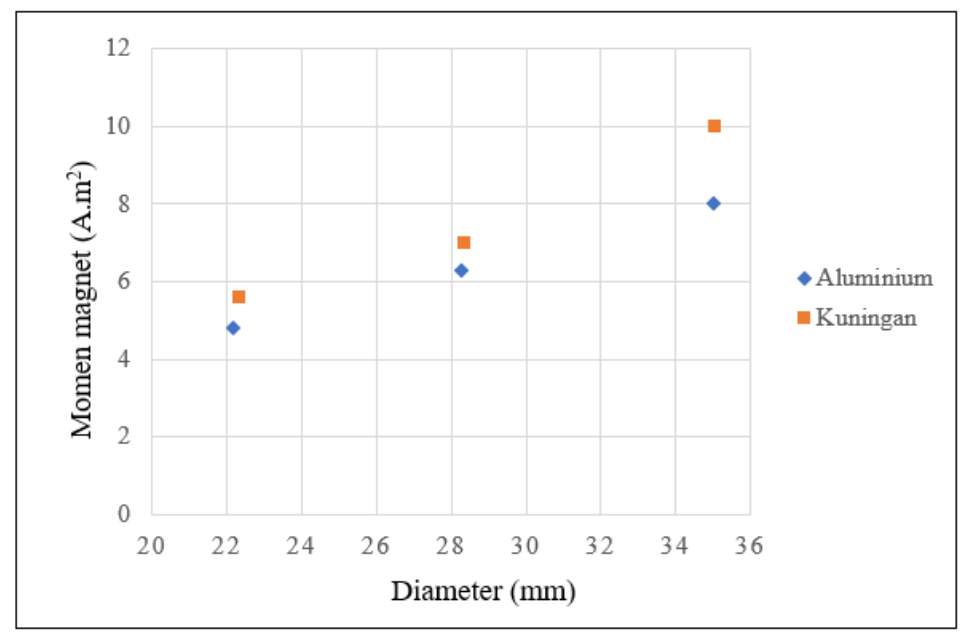

Gambar 5. Grafik momen magnet terhadap diameter dalam pipa aluminium dan kuningan.

Perlu digaris bawahi bahwa penelitian yang dilakukan ini lebih bertujuan pada menekankan metode. Peneliti ingin menunjukkan bahwa eksperimen dapat dilakukan dengan bantuan teknologi informasi. Maka dari itu, peneliti mendorong supaya para guru di sekolah dapat mengajak siswanya untuk melakukan eksperimen sederhana dengan bantuan teknologi. Diharapkan siswa menjadi lebih memahami fisika dan nantinya tertarik untuk menekuni bidang fisika.

\section{SIMPULAN DAN SARAN}

\subsection{Simpulan}

Dari penelitian yang telah dilakukan dapat disimpulkan bahwa nilai koefisien redaman magnetik berbanding terbalik dengan diameter dalam pipa dan berbanding lurus dengan suseptibilitas bahan. Nilai momen magnet berbanding lurus dengan diameter dalam pipa dan berbanding terbalik dengan koefisien konduktivitas bahan. Penelitian ini menekankan pada metode yaitu metode analisa video menggunakan software Logger Pro. Metode ini dapat digunakan di sekolah sehingga kegiatan eksperimen menjadi lebih menarik bagi siswa.

\subsection{Saran}

Ada beberapa hal yang perlu diperhatikan untuk dikembangkan dari penelitian ini bagi peneliti selanjutnya untuk melakukan variasi ketebalan pipa. Selain itu, nilai konduktivitas bahan dapat dihitung sesuai dengan bahan yang digunakan.

\section{UCAPAN TERIMA KASIH}

Kami mengucapkan terima kasih kepada Kepala Laboratorium Fisika Universitas Sanata Dharma karena telah memberikan fasilitas sehingga penelitian ini dapat berjalan dengan baik. Juga kepada Laboran Laboratorium Fisika yang telah menyiapkan segala hal yang diperlukan dalam penelitian ini. 


\section{DAFTAR PUSTAKA}

1. Suciarahmat A, Pramudya Y. Aplikasi Sensor Smartphone dalam Eksperimen Penentuan Percepatan Gravitasi. J Fis Indones. 2015;19(55):10-3.

2. Vogt P, Kuhn J. Analyzing simple pendulum phenomena with a smartphone acceleration sensor. Phys Teach [Internet]. 2012 Sep 10;50(7):439-40. Available from: https://doi.org/10.1119/1.4752056

3. Pili U, Violanda R, Ceniza C. Measurement of $\mathrm{g}$ using a magnetic pendulum and a smartphone magnetometer. Phys Teach [Internet]. 2018 Mar 16;56(4):258-9. Available from: https://doi.org/10.1119/1.5028247

4. Arribas E, Escobar I, Suarez CP, Najera A, Beléndez A. Measurement of the magnetic field of small magnets with a smartphone: a very economical laboratory practice for introductory physics courses. Eur J Phys [Internet]. 2015;36(6):65002. Available from: http://dx.doi.org/10.1088/0143-0807/36/6/065002

5. Setiawan B, Septianto RD, Suhendra D, Iskandar F. Measurement of 3-axis magnetic fields induced by current wires using a smartphone in magnetostatics experiments. Phys Educ [Internet]. 2017;52(6):65011. Available from: http://dx.doi.org/10.1088/1361-6552/aa83e3

6. Patrinopoulos M, Kefalis C. Angular velocity direct measurement and moment of inertia calculation of a rigid body using a smartphone. Phys Teach [Internet]. 2015 Nov 13;53(9):564-5. Available from: https://doi.org/10.1119/1.4935774

7. Gulo NK, Panuluh AH. Pengukuran Modulus Young Senar Pancing Dengan Metode Analisis Frekuensi Dawai. J Kumparan Fis. 2020;3(3):209-14.

8. Hia S, Panuluh AH. Pengukuran Modulus Geser Baja Menggunakan Analisis Osilasi PegasMassa. J Teor dan Apl Fis. 2021;9(1):1-8.

9. Mendoza-Arenas JJ, Perico ELD, Fajardo F. Motion of a damped oscillating sphere as a function of the medium viscosity. Eur J Phys [Internet]. 2009;31(1):129-41. Available from: http://dx.doi.org/10.1088/0143-0807/31/1/012

10. Oktova R, Diana N. Penentuan koefisien viskositas air menggunakan metode getaran pegas dengan koreksi kedalaman penetrasi dan koreksi efek dinding. Berk Fis Indones. 2013;5(1):25-34.

11. Rada MKD, Panuluh AH. Penggunaan Aplikasi Logger Pro untuk Menentukan Nilai Viskositas Air. J Ilmu Fis dan Pembelajarannya. 2021;5(1):28-35.

12. Ireson G, Twidle J. Magnetic braking revisited: activities for the undergraduate laboratory. Eur J Phys [Internet]. 2008;29(4):745-51. Available from: http://dx.doi.org/10.1088/01430807/29/4/009

13. Giancoli DC. Physics: principles with applications. Boston: Pearson; 2016.

14. Donoso G, Ladera CL, Martín P. Magnet fall inside a conductive pipe: motion and the role of the pipe wall thickness. Eur J Phys [Internet]. 2009;30(4):855-69. Available from: http://dx.doi.org/10.1088/0143-0807/30/4/018

15. Syed M, Nuessle N. What a Metal Pipe Can Teach You About Magnetism. Phys Teach [Internet]. 2019 Apr 18;57(5):330-3. Available from: https://doi.org/10.1119/1.5098925

16. Tipler PA, Mosca G. Physics for scientists and engineers. Macmillan; 2007. 